\title{
MJN \\ SAILING FREE TO THE OCEAN TOWARDS RECOVERY: FACILITATING THE CARE OF A PATIENT WITH SCHIZOPHRENIA THROUGH THE TIDAL MODEL
}

\author{
Ernyl Henry E. Redula* \\ College of Nursing, Cebu Normal University, Philippines \\ *Corresponding Author's Email: dbtcusctc@gmail.com
}

\begin{abstract}
During the critical events in life's voyage, the person may experience storms. At sometimes the ship may begin to take in the waves and the person may face the danger of drowning or shipwreck. The study aimed to explore the story towards recovery of a patient diagnosed with Schizophrenia. Utilizing the Tidal Model including its philosophical assumptions, the proponent sought to determine how this mental recovery model can be used in helping individuals resolved what needs to be acted now, to help answer present hitches in life, and to continue living an ordinary and meaningful life. It is also the goal of the study to ascertain what else can be done before for a patient with Schizophrenia in order to have a timely recovery and less frequent recurrence of the condition. Case study approach was used in order to answer the how and why inquiries concentrating more on the phenomenon that takes place in a real-life perspective. The Ten Tidal Commitments and Twenty Tidal competencies were integrated throughout the study taking into account the story narrated by the patient in regard to her needs towards recovery. The findings of this study showed that Tidal Model is indeed a valuable person-centered and collaborative approach in helping a schizophrenic client achieve its gradual and mental health recovery.
\end{abstract}

Keywords: Schizophrenia, Commitment, Competencies, Self, Others, World, Recovery, Ocean, Tidal

\section{INTRODUCTION}

During the critical events in life's voyage, the person may experience storms or even piracy. At sometimes the ship may begin to take in the waves and the person may face the danger of drowning or shipwreck. The person may need to be guided to a safe haven to undertake repairs or to recover from the trauma. Once the ship is repaired from the damage, or the person back to the path of recovery (Barker \& Buchanan-Barker, 2005).

Exposure to an overpowering situation, "resulting in helplessness in the face of intolerable danger, anxiety and instinctual arousal" precipitates and describes psychic traumatic events such as natural disasters, rape, incest, physical or mental torture, combat experiences, and catastrophic accidents are likely to generate a shipwrecking nightmare which then tends to increase the risk of maladaptive responses to that traumatic event (Antai-Otong, 2003).
A stressful or traumatic event could sometimes cause schizophrenia in some people who are vulnerable. Schizophrenia is a brain disorder that affects how a person acts, and how he or she perceives, and foresees the world. It alters the perception of reality wherein they may see or hear things that do not exist, speak in strange or confusing ways, believes that others are trying to harm them, or feel like they're being constantly watched (Antai-Otong, 2003).

A study by Spauwen (2016), reports that a new research study out of the Netherlands further strengthens the evidence that suggests that trauma is a casual factor in psychosis and likely in schizophrenia (that includes psychosis as one of the key symptoms). This study also confirms of the consensus view in the scientific community that schizophrenia is caused by a genetic or biological predisposition, and then later environmental chaos, or stresses that increases the risk or that could trigger the condition. 
Schizophrenia is becoming more widely viewed as a group of illnesses rather than a single condition. Schizophrenic people seem to be very distractible. It is very hard for them to focus on one topic for any length of time (Neeb, 2001). It seems to strike adolescents and young adults between the ages of 16 and 35, with women tending to experience the symptoms approximately 5 years later than males (NIMH, 1999).

Based on interaction of a number of factors, individuals could tend to develop schizophrenia. These factors include genetics, both physical and psychological environment, anatomic and functional systems, and the contribution of stressors (e.g., neurological dysfunction, psychobiological and environmental factors, alcohol and substance abuse and interpersonal relationships) (Lutz \& Warren, 2001). The predisposition to develop schizophrenia is created by changes within a person's physical, psychological, spiritual or cultural environments in conjunction with the presence of stressors. (AntaiOtong, 2003).

According to the World Health Organization (WHO, 2016), Schizophrenia affects approximately 1.6 percent of the population or more than 21 million people across all cultural groups. It is estimated that schizophrenia accounts for approximately 2.5 percent of all health care expenditures.

According to OCanghaile \& Delisi (2015), that the top brain disorder in the Philippines is schizophrenia. Many Filipinos who are affected by mental problems are now seeking cure and dealing them through medical management in mental institutions in the country. Out of more than 2,500 mentally ill patients in the participating health facilities, there were 1, 050 Filipino patients who are schizophrenic.

The researcher had a great interest in knowing how a schizophrenia patient who had a traumatic experience in the past could now begin to sail on through a vast ocean of experiences towards the voyage of life, goals and dreams, problems of living, and how seeing the future. As people are their narratives, the Tidal Model has shed light of interest to the researcher as it lures its core philosophical allegory from the Chaos Theory, here is a changeable - yet restricted - on how the water moves and flow and the power it holds like that of the waves in the sea is being compared to on human actions and experiences (Barker \& Buchanan-Barker, 2005). The researcher would want to know how mental recovery model can be used in helping individuals resolve what needs to be acted now, to help answer present hitches in life, and to continue living an ordinary and meaningful life. And lastly, the researcher also would want to ascertain what else can be done for a patient with schizophrenia in order to have a timely recovery and less frequent recurrence of the condition.

\section{METHODOLOGY}

The method that is being utilized is a design of qualitative research, known as case study. It answers how and why inquiries, provides situations when the researcher has marginal control over the happenings, and also obliges to concentrate on a phenomenon that takes place in a real-life perspective. Through the utilization of both quantitative and qualitative data, this method allows the intermediation to be designated, explained, and an in-depth exploration. It answers how and why questions, accommodates situations when the researcher has minimal control over the events, and requires a focus on phenomena that occur in a real-life context (Amerson, 2011). Giving emphasis to the patient's viewpoint of nursing care, it can be used as a creative alternative to traditional approaches to description.

To establish the researcher's understanding on the patients' present condition, he has utilized the Psychiatric Evaluation, Mental Status Examination and Interview Guide in Psychiatry as a Nursing Specialty of Cebu Normal University - College of Nursing (2012).

Standardized assessment tools provided by the Tidal Model Mental Health, Reclamation and Recovery of 2007 were also employed to integrate the Tidal Model principles, assumptions and commitments. The Nurse's Global Assessment of Suicide Risk (NGASR) Form adapted by Barker \& Buchanan-Barker, (2010) was utilized which assesses and determines the level of engagement between the patient and nurse by rating fifteen (15) predictors for the assessment risk, with values either One (1) to three (3). One (1) signifying low risk, two (2) signifying medium risk and three (3) high risk. The patient is made to score relevant events in her life. Results of which determines the level of engagement. The Tidal Model has four (4) levels of agreement. A total score of five (5) or lower indicates a low risk level to which engagement is to be done on a structured daily basis (Level Four). A score between six (6) and eight (8) indicates an intermediate level of risk to which a formal engagement process is to be done at least three times per day (Level Three).

A score between nine and eleven suggests a high 
level of risks which calls for a regular support by approximately every fifteen minutes all throughout the day coming from the nursing team throughout the entire day (Level Two). Lastly, a total score of twelve or higher signifies a risk of very high level, thereby letting the client have a persistent contact for support coming from a nurse or other mental health care professional (Level One).

In addition to this, other standardized assessment tools that were adapted from the Tidal Model Mental Health Reclamation and Recovery of 2007 were integrated in the Tidal Model principles and commitments: Holistic Assessment, establishes the person's world of experience in a phase that is important now and how that experience has now become to be very significant for the person; Personal Security Plan denotes a serious pace from being 'cared for' going towards 'self-care' or self-help, is how a person contributes to their own plan of care and; Tidal's Monitoring Assessment, which provides a unpretentious degree of the observed risk level - coming from the person and the perspective of the nurse to recognize on how to minimize the risk level; and One-to-one Session, is just like an usual chat in which it 'powers up' the client on what she can do for herself.

Moreover, a daily journal was utilized for assessment, gathering information and keeping track of her thoughts, emotions and activities on the day-to-day interaction that are significant for the study. Possessing a memoire out from a journal of the client's beliefs and emotional state assists them recognize the different traits coming out of their interpersonal proficiencies and periodically examines them from time to time. It gives the client an opportunity to see continuity of people relationships (Stuart \& Laraia, 2005). This way, the nurse can also note behavioral strengths that the patient has not yet identified that could help in recognizing and realizing them to her.

\section{RESULT}

Discussed below are the findings in the utilization of the Tidal Model on a client with Schizophrenia disorder based on the three domains: Self, World and Others:

\section{Self-Domain}

This is a case of a female, Filipino, 30 years old, single, a Roman Catholic, youngest of two siblings. The family is supported by her sister working in Manila. She lost her father when she was 21 years old due to Pneumonia. The client does not smoke nor drink. There is no known food and drug allergies and she is not in a relationship. She is a College graduate with an Associate in Information Technology degree. She was employed in toy store at year 2005, but resigned from work due to time constraints and work pressure. She was admitted for chief complaints of violent behavior, poor sleep and non-compliant to medications and a diagnosis of Schizophrenia Disorder.

In 2005, the client travelled to Bantayan Island for a vacation together with her two friends. Riding on a bus on their way back home, she and the other 8-10 passengers which included two of her friends were attacked by a thief. In the middle of their travel in the dark areas of Tabogon and Borbon, the thief then declared a "hold-up". The thief tried to take her bag and cellphone away from her but the patient engaged herself in a tug-of-war situation until the bag was taken away from her. The thief then punched her on the chest and slapped her on her left cheek. She and her friends reported this incident to her mom when they arrived home but nothing was done. Since then, the patient was experiencing episodes of nightmares, inability to sleep well during the night and incoherence. The client consulted in a psychiatric hospital in Cebu City three times already and was given Risperidone for medication. At first, the patient was religiously taking the prescribed take home medication but after then the patient refused and stopped taking because she thought that she was already well and the medication had no effect already. The patients' condition deteriorated after a month of noncompliance and no follow-up check-up was done. The patient then started hitting her mother without any reason, who is the only person staying together with her at home. She was also exhibiting pushing and throwing things inside the house. After the occurrence of those incidents, the patient then ran away from home and started hurting other people by throwing stones at them. This prompted the family to seek for medical attention.

At the time of study, patient had already stayed in the center for two weeks. Though she was observed not to pose harm to self and others, she was noted to have few episodes of self- talking, pacing from the hall to the garden area, and flight of ideas. But the patient was open and can communicate well since she is a college graduate. She expressed her preference on using Tagalog-Cebuano language as her way of conveying her story.

Physiological Needs: "Magpahulay, mag apil sa therapy ug makig sturya sa nurse kay makapahuwas sa akong 
gibati." (To rest, to join in the therapy and to talk with the nurse to ventilate my feelings.)

Knowledge deficit on the disorder: "Ganahan ko makahibaw unsa ni akong sakit nga Schizophrenia sir, Wa man kaayo ko explaini sa akong doktor bahin niana. (I want to know what my disorder is about called schizophrenia. My doctor did not explain it to me.)

Need for compliance to medication / treatment regimen: "Okay ra gyud ko sir, basta mutumar lang ko ug tambal..." (I am very okay sir when I take my medications)

Need for interventions to address verbalization of feelings and thoughts; and to alleviate anxiety: ".....mu ampo lang jud sa Ginoo, ni Mama Mary ug ni San Vicente, makig halobilo sa mga pasyente ngari ug sa mga madre." (To pray to God, Mother Mary and St. Vincent, to socialize with other patients and with the nuns.).

The results had manifested the personal wisdom of the patient to manage the risk and her need for help. She verbalized her intent in praying, conversing with patients and health care providers, verbalization of feelings and thoughts, eating a balanced diet and engage in participation of the therapy as her means to attain stability. She also mentioned her need for medical and nursing care and most of all family support. As a result, she had set her own care plan to help herself cope and foster emotional security, thus leading to eventual recovery. Different levels of care are needed at different times in the course of the disorder. Treatment effectiveness is a function of the severity of the disorder and the motivation of the individual to actively participate in managing it.

\section{World Domain}

Beginning from the Self domain, the person starts to share the experiences, with other people, in the person's society and community and slowly enters into the realm of the World Domain. The patient's needs in the World Domain are identified below:

Need to be accepted by the society at large and be free from social stigma: Kung sunggogon ko sa among mga siliningan kay ako tawgon ko nilag buang. (When my neighbors tease me as crazy!)

Need for closer ties with family: "Kaulion na kaayo ko. Ganahan nako mu balik sa amo-a. Kinahanglan ko naa sa balay kaya run adunay katabang si Mama nako sa balay kay siya ra man usa." (I want to go home. I want to return back home. I am needed at home so that my mother has a helping hand back home)

Need for livelihood for sustenance: Ganahan sad ko mangitag trabaho. Ok ra gyud nako nga maninda ra ko arun naa koy ikahatag nga para pang gasto sa balay." (I want to look for a job. It is fine with me to be selling so that I could give help for the expenses at home.)

As trust is now being the foundation and core, the patient willingly writes the language she would like to be understood. She now gains insights on how to pick up the broken pieces of her life. As she is laying down her plans in gaining control of her life, she now realizes who she is and what she wants for her future taking into account her struggles, fears, concerns and difficulties that was drowned on. She hangs on to the oar of her boat that led her to her hopes and aspirations that would lead her to embark on the shore of safety and most of all a brighter future. The nurse now stands as a beacon of light like a light house on an island to guide ships and boats to safety. The nurse encouraged the patient to do the changes she need to achieve recovery by letting the world acknowledge that her presence is still of importance. One of her concerns is the acceptance of her present condition towards her community and family as to avoid the social stigma that might worsen her condition. Family Support and the need for livelihood thrives on her mind set that would be of concern as of the moment as not to be a burden for the family and support for self.

\section{Others Domain}

In the Others Domain, the patient will cultivate consciousness of the various sources of support, people who are in the similar ship - the support groups. She will also improve mindfulness of how she can offer support and assistance to anybody who has similar situation, thus recognizing her value as a person.

In this domain, the patient emphasized on support groups. The biological basis for illness and symptoms provides a rationale for conducting groups made up of patients who suffer from the same ailments and problems. Having the same diagnosis increases the likelihood that clients can be helpful to one another as they learn together to cope with their illness. In order to have a normal life again, the patient was given the type and kind of assistance that she might need from the people surrounding her and including the health care professionals. The patient stated:

"Maayo unta nga adunay mga tawo nga parehas 
nakog kahimtang nga maka tabang or akong mahalobilo kung naa na ko sa gawas." (I hope there are people who has the same condition like mine who could help me or I might interact with when I get out from here.)

\section{DISCUSSION}

Supportive or therapeutic groups' help members cope with the sources of stress in their lives and focus on existing strengths (Kim \& Kim, 2001). Support groups focus on thoughts, feelings and behaviors. Group therapy is a helpful treatment method with patients with schizophrenia. Kanas (1991) described a short-term approach of nine meetings. The therapeutic goals include teaching clients how to cope up with their psychotic experiences and improve their interpersonal relationships. Members learn from one another's content and from the practice of interaction. Support groups purpose includes providing safety, avoiding anxiety, promoting trust, and decreasing isolation and loneliness (Antai-Otong, 2003).

Moreover, in this domain, the patient also stressed out on Family Support. Family strength has been delineated as healthy familial interactions and relationships that foster self-esteem and a positive outlook on life (Otto, 1962). Families are capable of withstanding and rebounding from crisis and distress because of their relational resilience. Relational resilience refers to the family's ability to mobilize resources and confront psychosocial and biological stresses effectively using adaptive coping, responses to foster a sense of collaboration, competence, and confidence in its members (Walsh, 1996).

"Maayo unta nga mu supporta gihapon sila ni mama ug ate sa akoang kahimtang kay wala gyud koy kwarta ikapalit ug tambal ug unta di lang ko nila pasagdan." (It would be better if my mother and sister would support me of my condition, because I really have no money to buy for my medication and that they just won't leave me alone).

We can now say that the patient verbalized her concern about her family support in terms of her medication and presence. Families function that influence healthy outcomes in times of crisis or change. Problem solving is the primary function that provides basic human needs through proper communication that is clear, congruent and direct. Family support is important in reinstating honesty in communication. It is a safe place to intervene and explore the underlying feelings that have been ignored within the family unit.
Furthermore, this domain also includes the community support. After-care involves the care occurring after a person's discharge from the psychiatric facility. The fear of being ridiculed and rejected of her community way back home makes her feel unwanted then becomes a fear of her self-confidence to show that she has fully recovered.

"Basin ila na sad ko ingnun ug buang sa akong mga silingan. Mayta musabot sila nako sa akong kahimtang" (My neighbors might call me crazy again. I hope that they would understand my situation).

The concern for acceptance and rejection of the community remains another problem for the patient. A person's recovery may be facilitated when the community or the environment incorporates empathy, understanding, affirmation, encouragement and acceptance. Prior to discharge, the community must be oriented of the situation that a member needs their total support for the full recovery of the client.

Recent studies indicate that successful treatment of persons with serious mental illnesses in the community requires a comprehensive and holistic early maintenance program to enhance outcomes, particularly those with first episode psychosis. (Birchwood, Todd \& Johnson, 1998).

\section{Way to Recovery}

By openly sharing her personal stories, using her own language, the patient had already made a concrete step in recovering control over her life. She did not only take into account her distress, problems of human living, concerns and difficulties but also her hope and aspirations for recovery and eventual normalcy. Past experiences and previous coping mechanisms were delved into to know what had worked for the patient and to establish better care plans. The patient then was able to identify her various needs in the domains of Self, World and Others and was guided by the nurse researcher to address these needs. She took time to accept and learn more of her disorder so she may be able to manage it appropriately as much as she can. She participated in various activities and sessions, with the goal of going back to her normal self again and live a normal life. Her conscious cooperation enabled her to discover her strengths and capabilities, believing in herself. The patient was deprived from family contact by her physician as part of her therapy.

On the last day of the nurse-client interaction, both 
parties expressed heartfelt gratitude for the existence of a caring relationship. The patient saw Tidal Model as a friendly approach, one that is not threatening, intimidating and authoritative. Opportunity was given to her to share her stories, through shoving her oar in the vast ocean to recovery making her feel like her ideas are important. She felt like talking with a colleague and not with someone in authority.

\section{CONCLUSION}

The findings showed that Tidal Model is indeed a valuable person-centered and collaborative approach in helping a schizophrenic client achieve gradual mental health recovery. It has placed in a higher premium - the client's family, livelihood and community support as the identified needs to help her reach to the shores of reality and recovery. Anchored by the guidance of the Tidal model, through its Ten Commitments and Twenty Competencies, and its assessment tools that were of great help in digging out the stories that were hidden, it moulded the client on her own realization, future plans and selfempowerment. The journey with the Tidal model, with its lasting elaboration on operating with the supremacy of the person's life story - focusing on her misery and the voyage back to recovery - delivered a venue for emerging the concept about 'caring with', but by the personal wisdom and voice of the patient and the listening ear of the nurse, both discovered solutions to sail together along the vast ocean with no one thrown overboard.

\section{Recommendations}

The author recommends that alongside with the psychiatric disorders, that the use of the model to clients with medical condition may be of great importance as to its casual effect of mental health and improvement of faster recovery. The model has to be applied for a longer duration of time in order to gather more data through asking questions as it is the simplest, yet often the most complex, form of assessment. It requires a very unusual mind to undertake the analysis of the obvious. In our efforts to understand 'who' the person is in our care, we need also to consider 'what' the person does, and 'what' might be the reason for him or her doing that rather than anything else. Through recognizing that we have no idea regarding our patients in our care, it is advised that there must be an initiative to understand better what is really going on with them. We do this by asking more and more curious questions.

\section{Conflict of Interests}

The authors declare that they have no conflict of interest.

\section{ACKNOWLEDGEMENT}

The authors are thankful to the institutional authority for completion of the work.

\section{REFERENCES}

Amerson, R. (2011). Making a case for the case study method. Journal of Nursing Education, 50(8), pp 427-428.

Antai-Otong, D. (2003). Psychiatric Nursing: Biological and Behavioral Concepts. Singapore: Thomson Learning Asia.

Barker, P. \& Buchanan-Barker, P. (2005). The Tidal Model: A Guide for Mental Health Professionals. London: Brunner-Routledge.

Barker, P. \& Buchanan-Barker, P. (2010). The tidal model of mental health recovery and reclamation: Application in acute care settings. Issues in Mental Health Nursing, 1(3), pp 171-180.

Birchwood, M., Todd, P. \& Jackson, C. (1998). Early intervention in psychosis: The critical period hypothesis. British Journal of Psychiatry, 172(S33), pp 53-59.

Kanas, N. C. (1999). Group Therapy with Schizophrenic Patients: A Short-Term Psycheducational and Support groups for Relatives coping with Chronic Schizophrenia. Archives of Psychiatric Nursing, 4, pp 343-353.

Kim, S. \& Kim, J. (2001). The Effects of Group Intervention for Battered Women in Korea. Archives of Psychiatric Nursing, 15(6), pp 257-264

Lutz, W. J. \& Warren, B. J. (2001). Symptomatology and Medication Monitoring for public mental health consumers: A cultural perspective. Journal of the American Psychiatric Nurses Association, 7(4), pp 115-124. 
National Institute of Mental Health (NIHM). (1999). Retrieved from: https://www.nih.gov/about-nih/what-wedo/nih-almanac/national-institute-mental-health-nimh

Neeb, K. (2006). Fundamentals of Mental Health Nursing, $3^{\text {rd }}$ edition. Philadelphia: F. A Davis Company. Ocanghaile, A. \& Delisi, L. (2015). Distinguishing Schizophrenia from Posttraumatic Stress Disorder with Psychosis. Current Opinion in Psychiatry, 28(3), pp 249-255.

Otto, R., Barker, W., Schwarz, D. \& Tjarksen, B. (1962). Laboratory testing of pharmaceutical wastes for biological control. Biotechnology \& Bioengineering, 4(2), pp 139-145.

Spauwen, J., Krabbendam, L., Lieb, R., Wittchen, H.U. \& van Os, J. (2006). Impact of Psychological Trauma on the Development of Psychotic Symptoms: Relationship with Psychosis Proneness. British Journal of Psychiatry, June(188), pp 527-533.

Stuart, G.W. \& Laraia, M.T. (2005). Principles and Practice of Psychiatric Nursing, $8^{\text {th }}$ edition. St. Louis: Mosby Inc. Walsh, F. (1996). The Concept of Family Resilience: Crisis and Challenge. Family Process, 35(3), pp 261-281.

World Health Organization (WHO) (2016). Schizophrenia. Retrieved from: http://www.who.int/mental_health/ management/schizophrenia/en/ 